\title{
Imunodiagnóstico da cisticercose em suíno experimentalmente infectado com ovos de Taenia solium, utilizando antígeno de escólex de Cysticercus cellulosae
}

\author{
[Immunodiagnosis of cysticercosis in swine experimentally infected with Taenia solium eggs, \\ using antigen of Cysticercus cellulosae scolex] \\ K.A. Soares, M.R.M. Silva, M.D. Poleti, A.A.M. Maia* \\ Departamento de Ciências Básicas - FZEA - USP \\ Av. Duque de Caxias Norte, 225 \\ 13635-900 - Pirassununga, SP
}

\begin{abstract}
RESUMO
Colheu-se sangue de sete suínos infectados com ovos de Taenia solium, semanalmente, durante 140 dias, para realizar ELISA no soro, utilizando antígeno de escólex (Es-Tso) de C. cellulosae. Em todos os animais, após o $21^{\circ}$ dia pós-infecção, houve incremento significativo de anticorpos $\mathrm{IgG}$, que assim se mantiveram até o final do experimento. A sensibilidade do ELISA variou entre 87,5 e 100\%. À necropsia, foram identificados 238 cisticercos. Seis suínos apresentaram pelo menos um cisto no coração, língua ou masseter. Não se observou correlação entre concentração de anticorpos e número de cisticercos identificados.
\end{abstract}

Palavras-chave: suíno, cisticercose, Cysticercus cellulosae, antígeno, ELISA

\begin{abstract}
Blood samples from seven swines infected with eggs of Taenia solium, were collected weekly during a period of 140 days. The ELISA was carried out in serum, using antigen from Cysticercus cellulosae scolex (Es-Tso). The antibody levels for all animals significantly increased and maintained constant from the $21^{\text {th }}$ day post-infection to the end of the experiment. The sensitivity of the ELISA test averaged between $87.5 \%$ and $100 \%$. At the necropsy, 238 cysticerci were identified. Six swines presented at least one cysticercus in one of the organs: heart, tongue or masseter. No correlation between concentration of antibodies and number of identified cysticerci at necropsy, was observed.
\end{abstract}

Keywords: swine, cysticercosis, Cysticercus cellulosae, antigen, ELISA

\section{INTRODUÇÃO}

A cisticercose, enfermidade parasitária que ocorre em criações de suínos em diversas regiões do mundo, constitui grave problema de saúde pública, uma vez que o parasita pode acometer o homem. O diagnóstico da cisticercose suína, mediante o exame clínico da língua in vivo, é pouco sensível $(70 \%)$, apesar da elevada especificidade $(100 \%)$, pois a localização do parasita pode não ser generalizada (The Cysticercus... 1993). Na rotina da inspeção sanitária realizada em frigoríficos, são examinados os músculos mastigadores (masseter e pterigóide), coração e língua, que pode não identificar animais com baixa infecção.

O enzyme linked immunossorbent assay (ELISA) é o teste sorológico mais indicado para o diagnóstico da cisticercose suína, dada à sua alta sensibilidade, especificidade e reprodutibilidade. Phiri et al. (2002), ao examinarem a língua de dois grupos de suínos em regiões endêmicas, encontraram cisticercos em $8,2 \%$ e $5,2 \%$ dos

Recebido em 9 de junho de 2004

Aceito em 19 de outubro de 2005

*Autor para correspondência (corresponding author)

E-mail:maia@fzea.usp.br

Apoio: Fapesp 
animais, enquanto a presença de anticorpos para a cisticercose determinados pelo ELISA nos grupos foi, respectivamente, $20,8 \%$ e $9,3 \%$. Sato et al. (2003) verificaram que $34 \%$ dos animais com exame clínico da língua negativo para a cisticercose apresentaram resultados positivos no ELISA.

Vários antígenos nativos obtidos de C. cellulosae foram utilizados no ELISA para o diagnóstico da cisticercose, porém o escólex do parasita é a fração que possui antígenos capazes de conferir alta sensibilidade e especificidade ao teste (Nascimento et al., 1987). Ev et al. (1999) verificaram em soros de pacientes humanos com neurocisticercose que as proteínas do escólex conferiram ao ELISA sensibilidade e especificidade de $100 \%$. O objetivo deste trabalho foi avaliar a dinâmica de produção de anticorpos em suínos com cisticercose utilizando antígeno de escólex de C. cellulosae.

\section{MATERIAL E MÉTODOS}

Sete suínos da raça Landrace, desmamados, procedentes de criação tecnificada e sabidamente negativos para cisticercose foram mantidos em instalações de biotério. Os ovos do parasita foram obtidos de pacientes com exames de fezes positivos para Taenia sp após tratamento com Niclosamida ${ }^{1}$, seguido da administração de um purgativo salino (Aluja et al., 1999). As tênias eliminadas foram lavadas por várias vezes em solução fisiológica contendo penicilina e estreptomicina, procedendo-se, em seguida, à retirada dos ovos das proglotes, que foram mantidos na mesma solução por um período de quatro semanas (Verastegui et al., 2000). O diagnóstico específico do parasita adulto baseouse nas ramificações das proglotes (Mayta et al., 2000). A padronização do inóculo foi realizada em câmara hemocitométrica. Com o auxílio de uma pipeta plástica, cada suíno, após contenção, recebeu por via oral 200.000 ovos de $T$. solium em solução fisiológica (Stevenson, 1983).

Antes da inoculação e a cada sete dias após a infecção (DAI), foram coletados aproximadamente $10 \mathrm{ml}$ de sangue da veia jugular, até os 140 DAI. Após centrifugação, o

${ }^{1}$ Bayer AG, Leverkusen, Germany soro foi separado em alíquotas e armazenado em freezer $\mathrm{a}-20^{\circ} \mathrm{C}$.

Semanalmente, a partir dos 40 DAI, realizou-se o exame macroscópico da língua e, após 140 DAI, realizou-se o abate dos animais para identificação e quantificação dos cisticercos por órgão ou músculos. A análise dos tecidos foi realizada mediante cortes finos e paralelos, com auxílio de bisturi, iniciando pela cabeça até os músculos dos membros posteriores.

O antígeno de escólex foi preparado seguindo as recomendações de Pinto et al. (2000) com algumas modificações. Após o descongelamento, os cisticercos foram mantidos em placa de petri contendo solução fisiológica, em banho de gelo. Com auxílio de bisturi e pinça, foi realizada a separação da membrana e do escólex. Os escólexes foram acrescidos de pequeno volume de solução físiológica e homogeneizados em homogeneizador de Potter, em banho de gelo. Essa solução, ainda em banho de gelo, foi submetida ao ultra-som ${ }^{2}$, a $20 \mathrm{kHz}$ por quatro vezes, durante 30 segundos, com intervalos de 30 segundos. Posteriormente, a solução foi centrifugada a $15.000 \mathrm{~g}$, à temperatura de $4^{\circ} \mathrm{C}$, durante 30 minutos. Ao sobrenadante foi adicionado $\mathrm{PMSF}^{3} 1 \mathrm{mM}$. A dosagem de proteína foi realizada pelo método de Braford (1976).

Em seguida, foi realizada a padronização do ELISA testando as variáveis concentração antigênica, diluição do soro, título do conjugado e tempo e temperatura de incubação (Pinto et al., 2000) utilizando um soro padrão positivo e 10 soros negativos. A média de absorbâncias das amostras de suínos sabidamente negativos para cisticercose determinadas pelo ELISA foram acrescidas de duas vezes o desvio-padrão calculado, obtendo-se, assim, o cut-off. As amostras que apresentaram absorbância maior do que o cut-off foram consideradas positivas.

Nos soros dos suínos foi realizada pesquisa de anticorpos IgG pelo ELISA. Os procedimentos para a realização do ELISA foram: sensibilização prévia de placas de fundo plano ${ }^{4}$ com o antígeno de escólex na concentração de $0,5 \mu \mathrm{g}$ diluídos em $100 \mu \mathrm{l}$ de tampão carbonato/bicarbonato a $0,5 \mathrm{M}$,

\footnotetext{
${ }^{2}$ USC 500, Unique, São Paulo, SP, Brasil

${ }^{3}$ Sigma Chemical Company, St. Louis, MO, USA

${ }^{4}$ Costar, Coming, USA
} 
$\mathrm{pH} 9,6$, por cavidade; incubação das placas à temperatura ambiente por uma hora e depois a $4^{\circ} \mathrm{C}$ por 14 horas e lavagem das placas utilizando $100 \mu 1$ de PBS contendo tween 20 (PBS-T) a $0,05 \%$, por seis vezes durante um minuto, seguida de bloqueio com leite desnatado a $5 \%$, dissolvido em PBS. Foram pipetados $150 \mu \mathrm{l}$ da solução de bloqueio em cada cavidade e realizada nova incubação por uma hora. Após novo ciclo de lavagens sucessivas, o soro foi diluído em PBS-T contendo leite desnatado a $1 \%$, na proporção 1:100 e distribuído ao volume de $100 \mu \mathrm{l}$ por cavidade. As placas foram submetidas à temperatura de $37^{\circ} \mathrm{C}$ durante uma hora. Depois de nova lavagem, foram adicionados $100 \mu$ l por cavidade do conjugado soro de coelho anti-IgG total de suíno marcado com peroxidase ${ }^{6}$, diluído na proporção $1: 10000$, em solução PBS-T e leite desnatado a $1 \%$. As placas foram incubadas a $37^{\circ} \mathrm{C}$ por uma hora. Em seguida, repetiu-se a etapa de lavagem, adicionou-se $100 \mu \mathrm{l}$ do substrato 3,3',5,5' tetrametilbenzidina $(\mathrm{TMB})^{6}$ por cavidade. As placas foram deixadas à temperatura ambiente $\mathrm{e}$ ao abrigo da luz. Após oito minutos, a reação enzimática foi interrompida com $100 \mu \mathrm{l}$ de ácido sulfúrico $2 \mathrm{~N}$ por cavidade. A leitura foi realizada em leitor de ELISA $^{7}$ em comprimento de onda de $450 \mathrm{~nm}$.

\section{RESULTADOS}

Não foi detectada a presença de cisticercos no exame in vivo da língua dos animais infectados, porém foram encontrados 238 cisticercos no exame post-mortem. Todos os cisticercos foram considerados viáveis, uma vez que se apresentavam translúcidos e com escólex visível, observado através da membrana.

Quanto à distribuição (Tab. 1), verificou-se que $58(24,4 \%)$ cisticercos foram identificados na musculatura dos membros anteriores, 68 (28,6\%) na musculatura dos membros posteriores e 47 $(19,8 \%)$ em músculos da região dorsal. Seis animais apresentaram pelo menos um cisto no coração, língua ou masseter, sendo identificados nesses locais 43 cisticercos. Em um suíno $\left(n^{\circ} 2\right)$

\footnotetext{
${ }^{5}$ Molico, Nestlé, Brasil

${ }^{6}$ Sigma Chemical Company, St. Louis, MO, USA

${ }^{7}$ Labsystems Multiskan, Finlândia
}

foi identificado apenas um cisto localizado em músculo da região posterior.

A Fig. 1 apresenta as absorbâncias determinadas pelo ELISA utilizando o antígeno de escólex. Os valores em absorbância elevaram-se a partir do sétimo dia de infecção, com resultados positivos no ELISA aos 21 dias e, a partir daí, com oscilações ao longo da infecção. Os animais de $\mathrm{n}^{\mathrm{o}} 1$ a 6 sempre apresentaram resultados sorológicos positivos. Os resultados positivos do ELISA para o animal de $n^{0} 7$ foram muito próximos ao cut-off calculado, sendo o teste imunoenzimático negativo nos dias 49, 70 e 91.

Com base nos valores do cut-off, foi calculada a sensibilidade do ELISA nos dias 21, 28, 49, 70, 91, 112 e 133 nos soros dos suínos experimentalmente infectados (Fig. 2). A partir do dia 21 , a sensibilidade do teste variou entre 85,7 e $100 \%$.

\section{DISCUSSÃO}

A ausência de cisticercos na língua dos suínos infectados experimentalmente confirma a baixa sensibilidade do exame ante-mortem, o que ocorre principalmente em casos de baixa infecção (The cisticercus..., 1993). Phiri et al. (2002) também examinaram a língua de dois grupos de suínos naturalmente infectados procedentes de regiões endêmicas, encontrando cisticercos em $8,2 \%$ e $5,2 \%$ dos animais, enquanto no ELISA foram verificados anticorpos em $20,8 \%$ no primeiro grupo e $9,3 \%$ no segundo. Esses resultados mostram que, além do exame clínico para a pesquisa da cisticercose, também deve ser realizado o teste sorológico de alta sensibilidade. $\mathrm{Na}$ necropsia foram encontrados apenas 238 cisticercos. Apesar do baixo parasitismo, a pesquisa da cisticercose no coração, língua e masseter, locais indicados na rotina de inspeção, identificou seis $(85,7 \%)$ animais infectados. Deve-se ressaltar que a pesquisa dos parasitas foi realizada em condições de laboratório, em que cada músculo ou órgão foi minuciosamente examinado. $\mathrm{O}$ grande número de abates diários em matadouros inviabiliza o exame detalhado de órgãos e tecidos. Boa et al. (2002) verificaram em suínos naturalmente infectados $10,6 \%$ dos cisticercos em músculos onde é realizada a inspeção sanitária. 
Tabela 1. Distribuição dos cisticercos em suínos experimentalmente infectados com ovos de Taenia solium

\begin{tabular}{|c|c|c|c|c|c|c|c|c|c|}
\hline \multirow{2}{*}{ Órgão/região } & \multicolumn{7}{|c|}{ Suíno } & \multirow{2}{*}{ Total } & \multirow{2}{*}{$\%$} \\
\hline & 1 & 2 & 3 & 4 & 5 & 6 & 7 & & \\
\hline$\overline{\text { Coração }}$ & 9 & 0 & 1 & 0 & 2 & 4 & 4 & 20 & 8,4 \\
\hline Diafragma & 4 & 0 & 0 & 0 & 2 & 0 & 3 & 9 & 3,78 \\
\hline Língua & 5 & 0 & 0 & 0 & 1 & 3 & 0 & 9 & 3,78 \\
\hline Masseter & 0 & 0 & 0 & 2 & 1 & 7 & 4 & 14 & 5,88 \\
\hline Região cervical & 0 & 0 & 0 & 0 & 0 & 2 & 0 & 2 & 0,84 \\
\hline Região esofágica & 0 & 0 & 0 & 0 & 0 & 0 & 1 & 1 & 0,42 \\
\hline Membros anteriores & 13 & 0 & 3 & 3 & 4 & 28 & 7 & 58 & 24,38 \\
\hline Membros posteriores & 7 & 1 & 1 & 4 & 8 & 32 & 15 & 68 & 28,57 \\
\hline Região dorsal & 18 & 0 & 0 & 2 & 6 & 9 & 12 & 47 & 19,75 \\
\hline Região da nuca & 2 & 0 & 1 & 0 & 4 & 0 & 1 & 8 & 3,36 \\
\hline Região maxilar & 2 & 0 & 0 & 0 & 0 & 0 & 0 & 2 & 0,84 \\
\hline Total por animal & 60 & 1 & 6 & 11 & 28 & 85 & 47 & 238 & 100 \\
\hline
\end{tabular}

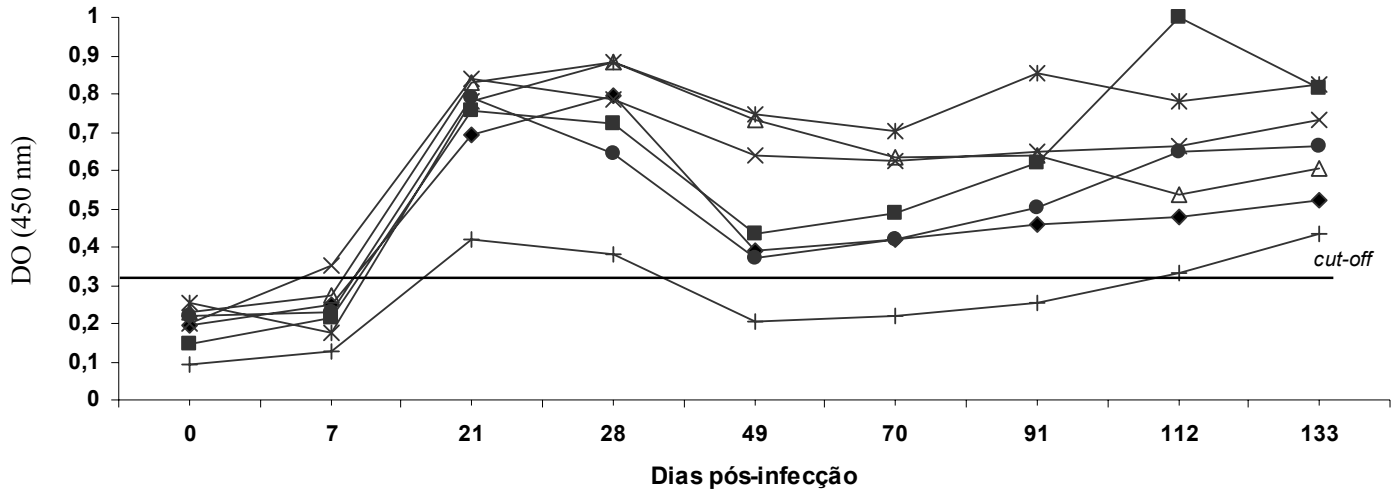

Suíno $1 \rightarrow$ Suíno $2 \multimap$ Suíno $3 \rightarrow$ Suíno $4 \rightarrow$ Suíno $5 \multimap$ Suíno $6 \multimap$ Suíno 7

Figura 1. Resultados do ELISA utilizando antígeno de escólex de Cysticercus cellulosae em soros de suínos experimentalmente infectados (cut off $=0,325$ ).

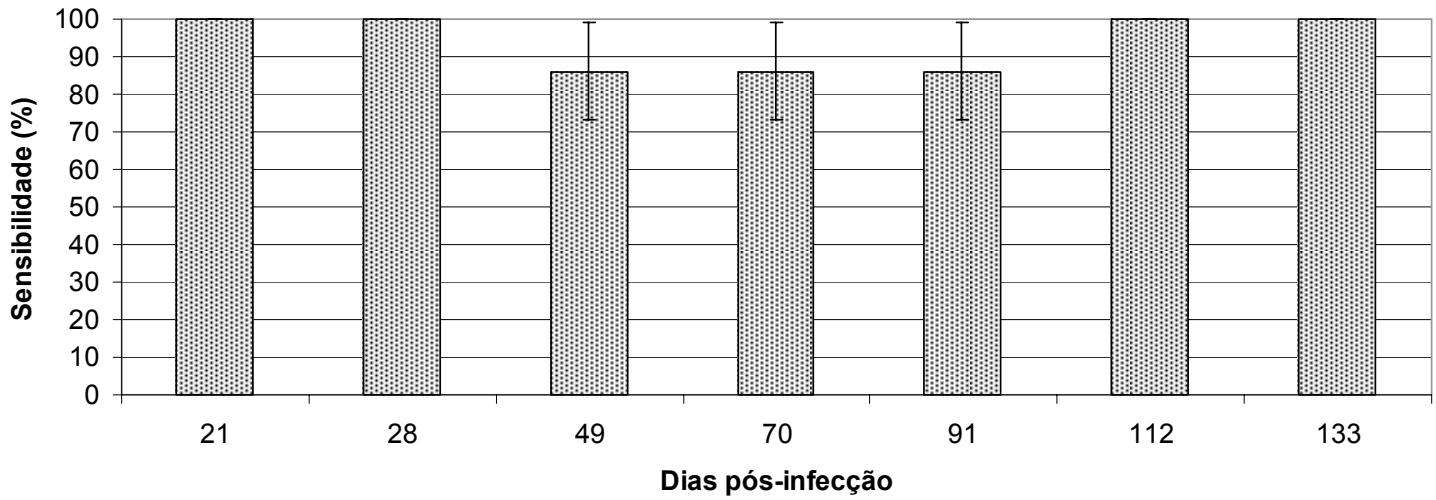

霜 Ag Es-Tso

Figura 2. Sensibilidade do ELISA utilizando o antígeno de escólex de Cysticercus cellulosae em soros de suínos experimentalmente infectados. 
Todos os cisticercos identificados eram viáveis e apresentavam uma membrana translúcida que envolvia o escólex invaginado mergulhado em líquido vesicular. A maior sobrevivência do parasita no hospedeiro pode ser atribuída à imunotolerância, pois ele utiliza mecanismos para evadir-se da resposta imune, minimizando ou até mesmo escapando de suas ações (Del Brutto et al., 1988).

O número de cistos identificados nos animais foi pequeno, mesmo com a grande quantidade de ovos administrados. A baixa fertilidade deles pode ser um dos motivos da baixa infectividade, em razão do longo período de armazenamento, ainda que tenham sido adotadas as recomendações de conservação preconizada em vários trabalhos (Stevenson, 1983; Lightowlers et al., 1996; Mayta et al., 2000; Verastegui et al., 2000). Nguekam et al. (2003) mantiveram ovos de $T$. solium em solução salina à temperatura de $4^{\circ} \mathrm{C}$ por 24 horas e verificaram pequena recuperação de larvas em suínos infectados experimentalmente, o que pode ser atribuído à baixa viabilidade dos ovos.

A partir do $21^{\circ}$ DAI os valores em absorbâncias aumentaram em todos os animais (Fig. 1). Santamaria et al. (2002) observaram que suínos infectados com ovos de T. solium apresentaram anticorpos somente 30 dias após a infecção, e Smith et al. (1991) verificaram, a partir de antígenos de fluido cístico de cisticerco de $T$. hydatigena, que os maiores valores em absorbância em bovinos com cisticercose ocorreram entre 40 e 60 dias após a infecção. Os títulos de anticorpos crescentes ao longo do parasitismo podem estar relacionados com a existência de cisticercos viáveis, metabolicamente ativos, produzindo e secretando substâncias que estimulam o sistema imunológico do hospedeiro (Flisser et al., 1990).

Não se observou correlação direta entre o número de cisticercos encontrados à necropsia e os valores em absorbância determinados pelo teste imunoenzimático (Fig. 1). O suíno $\mathrm{n}^{\mathrm{o}} 7 \mathrm{com}$ 47 cisticercos, apresentou os menores valores em absorbância ao longo da infecção, enquanto o de $\mathrm{n}^{\mathrm{o}} 2$, com apenas um parasita, comportou-se de maneira semelhante àqueles que apresentaram entre seis e 80 cisticercos. Esse comportamento pode estar relacionado com a resposta individual do hospedeiro. Em suínos com cisticercose natural, Sato et al. (2003) verificaram que somente animais com mais de 16 cisticercos apresentaram resultados positivos no ELISA. Nguekam et al. (2003) correlacionaram a positividade do ELISA com a presença de cisticercos não calcificados.

A sensibilidade do ELISA entre 85,7 e 100\% verificada no curso da infecção é semelhante aos resultados obtidos no diagnóstico da neurocisticercose humana encontrados em outras pesquisas (Nascimento et al., 1987; Ev et al., 1999), em que frações antigênicas procedentes de escólex de C. cellulosae conferiram alta sensibilidade e especificidade ao teste sorológico. Com base nestes resultados pode-se afirmar que esse antígeno é importante para o diagnóstico da cisticercose suína, pois pode identificar animais com baixo parasitismo e em estágios iniciais da infecção.

\section{REFERÊNCIAS BIBLIOGRÁFICAS}

ALUJA, A.S.; VILLALOBOS, A.N.M.; PLANCARTE, A. et al. Taenia solium cysticercosis: immunity in pigs induced by primary infection. Vet. Parasitol., v.81, p.129$35,1999$.

BOA, M.E.; KASSAKU, A.A.; WILLINGHAM III, A.L. et al. Distribution an density of cysticerci of Taenia solium by muscle groups and organs in naturally infected local finished pigs in Tanzania. Vet. Parasitol., v.106, p.155164, 2002.

BRADFORD, M.M. A rapid and sensitive method for the quantification of microgram quantities of protein utilizing the principle of protein dye binding. Anal. Biochem, v.263, p.1626-1630, 1976.

DEL BRUTTO, O.J.D.; GARCÍA, E.; TALÁMAS, O. et al. Sex-related severity of inflammation in parenchymal brain cysticercosis. Arch. Intern. Med., v.148, p.544-546, 1988.

EV, L.V.; MAIA, A.A.M.; PIANETTI, G. et al. Imunological evaluation of a $26-\mathrm{kDa}$ antigen from Taenia solium larvae for specific immunodiagnosis of human neurocysticercosis. Parasitol. Res., v.85, p.98-102, 1999.

FLISSER, A.; GONZALEZ, D.; PLANCARTE, A. et al. Praziquantel treatment of brain and 
muscle porcine Taenia solium cysticiercosis. 2 immunological and cytogenetic studies. Parasitol. Res., v.76, p.640-2, 1990.

LIGHTOWLERS, M.W.; ROLFE, R.; GAUCI, C.G. Taenia saginata: vacination against cysticercosis in cattle with recombinant oncosphere antigens. Exp. Parasitol., v.84, p.330-38, 1996.

MAYTA, H.; TALLEY, A.; GILMAN, R.H. et al. Differentiating Taenia Solium and Taenia Saginata infection by simple hematoxylin - eosin etaining and PCR restrition enzyme analysis. $J$. Clin. Microbiol., v.38, p.133-137, 2000.

NASCIMENTO, E.; NOGUEIRA, P.M.P.; TAVARES, C.A.P. Improved immunodiagnosis of human cysticercosis with scolex protein antigens. Parasitol. Res., v.73, p.446-450, 1987.

NGUEKAM, A.; ZOLI, A.P.; VONDOU, L. et al. Kinetcs of circulating antigens in pigs experimentally infected with Taenia solium eggs. Vet. Parasitol., v.111, p.323-332, 2003.

PHIRI, I.K.; DORNY, P.; GABRIEL, S. et al. The prevalence of porcine cysticercosis in eastern and southern provinces of Zambia. Vet. Parasitol., v.108, p.31-39, 2002.

PINTO, P.S.A.; VAZ, A.J.; GERMANO, P.M.L. et al. Performance of the ELISA test for swine cysticercosis using antigens of Taenia solium and
Taenia crassiceps cysticerci. Vet. Parasitol., v.88, p.127-130, 2000.

SANTAMARIA, E.; PLANCARTE, A.; ALUJA, A.S. The experimental infection of pigs with different numbers of Taenia solium eggs: immune response and efficiency of establishment. J. Parasitol., v.88, p.69-73, 2002.

SATO, M.O.; YAMASAKI, H.; SAKO, Y. et al. Evaluation of tongue inspection and serology for diagnosis of Taenia solium cysticercosis in swine: usefulness of ELISA using purified glycoproteins and recombinant antigen. Vet. Parasitol., v.2493, p.1-14, 2003.

SMITH, H.J.; SNOWDON, K.E.; FINLAY, R.C. Serological diagnosis of Cysticercosis by an Enzyme-linked Immunossorbent assay in experimentally infected cattle. Vet. Res., v.55, p.274-276, 1991.

STEVENSON, P. Observations on the hatching and activation of fresch Taenia saginata eggs. Ann. Trop. Med. Parasitol., v.77, p.399-404, 1983.

THE CYSTICERCUS working group in Peru: the marketing of cycticercosis pigs in Sierra of Peru. Bull. WHO, v.71, p.223-228, 1993.

VERASTEGUI, M.; GONZALEZ, A.; GILMAN, R.H. et al. Experimental infection model for Taenia solium cysticercosis in swine. Vet. Parasitol., v.94, p.33-44, 2000. 